\title{
Modulation and Protection Effects of Antioxidant Compounds against Oxidant Induced Developmental Toxicity in Zebrafish
}

\author{
Nuria Boix ${ }^{1,2, *}$, Elisabet Teixido ${ }^{1,2} \mathbb{D}^{\text {, Ester Pique }}{ }^{1,2}$, Juan Maria Llobet ${ }^{1,2}$ and \\ Jesus Gomez-Catalan 1,2 \\ 1 Toxicology Unit, Pharmacology, Toxicology and Therapeutical Chemistry Department, Pharmacy School, \\ University of Barcelona, Avda Joan XXIII s/n 08028 Barcelona, Spain; eteixido1511@ub.edu (E.T.); \\ esterpique@ub.edu (E.P.); jmllobet@ub.edu (J.M.L.); jesusgomez@ub.edu (J.G.-C.) \\ 2 INSA-UB Nutrition and Food Safety Research Institute, University of Barcelona, \\ Food and Nutrition Torribera Campus, Prat de la Riba 171, 08921 Santa Coloma de Gramenet, Spain \\ * Correspondence: nuriaboix@ub.edu; Tel.: +34-934-020-277
}

Received: 22 July 2020; Accepted: 4 August 2020; Published: 8 August 2020

\begin{abstract}
The antioxidant effect of compounds is regularly evaluated by in vitro assays that do not have the capability to predict in vivo protective activity or to determine their underlying mechanisms of action. The aim of this study was to develop an experimental system to evaluate the in vivo protective effects of different antioxidant compounds, based on the zebrafish embryo test. Zebrafish embryos were exposed to tert-butyl hydroperoxide (tBOOH), tetrachlorohydroquinone (TCHQ) and lipopolysaccharides from Escherichia coli (LPS), chemicals that are known inducers of oxidative stress in zebrafish. The developmental toxic effects (lethality or dysmorphogenesis) induced by these chemicals were modulated with N-acetyl L-cysteine and $\mathrm{N \omega}$-nitro L-arginine methyl ester hydrochloride, dimethyl maleate and DL-buthionine sulfoximine in order to validate the oxidant mechanism of oxidative stress inducers. The oxidant effects of $\mathrm{tBOOH}, \mathrm{TCHQ}$, and LPS were confirmed by the determination of significant differences in the comparison between the concentration-response curves of the oxidative stress inducers and of the modulators of antioxidant status. This concept was also applied to the study of the effects of well-known antioxidants, such as vitamin E, quercetin, and lipoic acid. Our results confirm the zebrafish model as an in vivo useful tool to test the protective effects of antioxidant compounds.
\end{abstract}

Keywords: oxidative stress; zebrafish embryo; in vivo model; antioxidant effect

\section{Introduction}

Reactive oxygen species (ROS) and reactive nitrogen species (RNS) are products of cellular metabolism, which play a dual role in beneficial and deleterious effects over different organs [1]. Aerobic organisms have antioxidant defenses to protect cells from oxidative damage. These defenses can be enzymatic (antioxidant enzymes) or non-enzymatic (antioxidant compounds) [2]. The imbalance between reactive metabolite production and antioxidant defenses in the organism is denominated oxidative stress (OS) and can produce potential detrimental effects in the organisms [3]. The consequences of OS can be very variable depending on the reactive species implicated, the subcellular structure where they are generated, the organs or tissues implicated in the effect, the genetic characteristics of the organism or developmental stage, among other factors. It is a phenomenon which has been related to different processes (aging, cancer, diabetes, cardiovascular and neurodegenerative diseases, etc.) as it can damage and inhibit the normal function of lipids, proteins, and DNA [4]. 
Antioxidants are chemicals that can inhibit or prevent oxidation processes. Such compounds can be produced within the human body or absorbed from dietary intake [5]. The antioxidant capacity of compounds is usually evaluated by in vitro techniques as the oxygen radical absorbance capacity (ORAC) or the total radical-trapping antioxidant parameter (TRAP), which are useful for the high-throughput screening of the antioxidative or radical-scavenging capacities of the compounds [6]. There are also cell-culture approaches, such as the cell-based antioxidant assay (CAA), which uses Caco-2 cells that allow for the study of intracellular influence of antioxidant chemicals [7]. These in vitro assays and biological techniques, which are regularly used to evaluate antioxidant capacity, do not have predictive capability for the protective activity that natural compounds have in vivo, or to determine their underlying mechanisms of action [8]. In vivo assays of antioxidant capacity of natural compounds have been performed in mice [9], in rats [10], and using other animal models, such as Caenorhabditis elegans [11] and adult zebrafish [12]. However, until now none of these in vivo models have been established and validated to systematically evaluate the protective effects of natural compounds.

Zebrafish (Danio rerio, ZF) is a tropical fish of the Cyprinidae family. The ZF embryo is considered a potential tool for investigating environmental exposures with direct relation to human health [13]. The ZF embryo presents multiple advantages, from which it can be highlighted that it is an in vivo model which studies the whole organism, with the main characteristics of an in vitro model: easy maintenance, large number of offspring, rapid embryonic development, possibility to combine with other biochemical, cellular and molecular techniques, screening of compounds, application to high-throughput methods, etc. [14-16]. The ZF embryo has been used as a model to study alterations and diseases related to OS mechanisms: inflammation [17], senescence [18], teratogenicity [19], neurodegenerative [20], and cardiovascular diseases [21]. Furthermore, ZF presents antioxidant genes and enzymes to protect them against OS effects. These defenses are analogous to mammalian antioxidant systems [22,23]. The protective effects of some antioxidants against exposure to OS inducers in ZF embryos have been studied with the objective to investigate the antioxidant mechanisms of action and demonstrate the usefulness of these antioxidants against oxidative damage [19,24,25].

The aim of the present work was to design an experimental system based on the ZF embryo test, which could be the basis for the study of in vivo protective effects of chemicals with antioxidant activity against oxidant-induced developmental toxicity in ZF embryos.

\section{Materials and Methods}

\subsection{Chemicals and Solution Preparation}

Tetrachlorohydroquinone (TCHQ, CAS number 87-87-6), lipopolysaccharides from Escherichia coli 0111:B4 (LPS), Nw-nitro L-arginine methyl ester hydrochloride (L-NAME, CAS number 51298-62-5), DL-buthionine sulfoximine (BSO, CAS number 5072-26-4), ( \pm )- $\alpha$-tocopherol (vitamin E, CAS number 10191-41-0), ( \pm )- $\alpha$-lipoic acid (lipoic acid, CAS number 1077-28-7), and quercetin hydrate (quercetin, CAS number 337951) were obtained from Sigma-Aldrich, Madrid, Spain. Tert-butyl hydroperoxide (tBOOH, CAS number: 75-91-2) was acquired from TCI Europe and N-acetyl-L-cysteine (NAC, CAS number 616-91-1) and diethyl maleate (DEM, CAS number 141-05-9) were obtained from Cymit Química, Barcelona, Spain.

$\mathrm{tBOOH}, \mathrm{LPS}, \mathrm{NAC}$, and DEM were directly dissolved in 0.3X Danieau's buffer $(17.4 \mathrm{mM} \mathrm{NaCl}$; $0.23 \mathrm{mM} \mathrm{KCl} ; 0.12 \mathrm{mM} \mathrm{MgSO} .7 \mathrm{H}_{2} \mathrm{O} ; 0.18 \mathrm{mM} \mathrm{Ca}\left(\mathrm{NO}_{3}\right)_{2} ; 1.5 \mathrm{mM}$ HEPES (N-(2-hydroxyethyl) piperazine-N'-(2-ethanesulfonic acid); $\mathrm{pH} 7.4)$. TCHQ, vit. E, quercetin, and lipoic acid were dissolved in $100 \%$ dimethyl sulfoxide (DMSO, Sigma-Aldrich, Madrid, Spain) and subsequently diluted in $0.3 \times$ Danieau's buffer to a final DMSO concentration of $0.05 \%(v / v)$.

Our previous experience with $0.05 \%$ DMSO in $0.3 \times$ Danieau's buffer clearly indicates that it does not produce any effects in lethality or dysmorphogenesis in ZF embryos, and it was not expected to modify the toxicity of the compounds. Moreover, DMSO is only expected to modify the permeability of chemicals if used at higher concentrations $>0.1 \%$ [26]. 
Concentrations of all chemicals are expressed in molarity, except for LPS that is given as $\mu \mathrm{g} / \mathrm{mL}$, due to the variable molecular mass of LPS, as it is part of the outer membrane of bacteria-in this case, Escherichia coli.

\subsection{Animals and Embryo Production}

Adult wild type ZF (BCN Piscicultura Iberica; Terrassa, Spain) were kept in aquariums with a closed flow-through system at $26 \pm 1{ }^{\circ} \mathrm{C}$ and $10-14 \mathrm{~h}$ constant dark-light cycle. Females and males were housed separately and fed with commercial flakes and brine shrimp (Ocean Nutrition, San Diego, USA). The day before the experiments, females and males were transferred to a breeding tank (10 females; 8 males). ZF embryos were collected within $1 \mathrm{~h}$ after the onset of lights in the morning. They were extensively cleaned, and fertilized eggs were staged according to [27] and selected for subsequent exposure under a dissection stereomicroscope (Motic SMZ168, Motic China Group, LTD., Luwan, Shanghai, China). The study was approved by the Ethic Committee for Animal Experimentation of the University of Barcelona and by the Department of Environment and Housing of the Generalitat de Catalunya with license number DAAM 7971.

\subsection{Exposure of Zebrafish Embryos to Oxidative Stress Related Compounds}

To characterize the effects on embryonic development produced by compounds related to OS, ZF embryos were exposed to OS inducers, modulators of antioxidant status and antioxidants. For compounds which were dissolved in DMSO and diluted with Danieau's buffer, a vehicle negative control group with $0.05 \%$ DMSO in $0.3 \times$ Danieau's buffer was assayed.

Exposures to antioxidants and to modulators were performed from 2 to $26 \mathrm{~h}$ post-fertilization (hpf) in order to select, for each of the compounds of study, the highest concentration at which any effect in lethality or in embryonic development was observed (maximum tolerable concentration, MTC). From 26 to 50 hpf, embryos were incubated with $0.3 \times$ Danieau's buffer with or without DMSO, depending on the dissolution of the compound of study.

Exposure to OS inducers was conducted from 26 to $50 \mathrm{hpf}$ to select the working concentrations of these compounds for the experimental design. In this case, from 2 to $26 \mathrm{hpf}$, embryos were incubated with Danieau's buffer with or without DMSO, depending on the dissolution of the compound of study.

Exposure of ZF embryos was semi-static and was carried out in 6-well plates (Greiner Bio-one, Frickenhausen, Germany). Ten embryos per group were selected and randomly distributed into the wells and filled with $5 \mathrm{~mL}$ of the corresponding solution of the compound. Embryos were incubated at $26 \pm 1{ }^{\circ} \mathrm{C}$ with a dark-light cycle of 10-14 h. Renewal of the medium and of the solutions was made every $24 \mathrm{~h}$. Evaluation of the embryos was performed at different time points. Lethality was determined at 8,26 , and $50 \mathrm{hpf}$ based on egg coagulation, the absence of tail detachment, or somite formation and the absence of heartbeat [28]. Dysmorphogenic effects were evaluated at 50 hpf by the total morphological score system described by [29]. For each compound of study, at least three independent experiments were performed using embryos from different spawning events $(n=3)$.

The percentage of lethality and of dysmorphogenesis was calculated per compound at every tested concentration, and the concentration-response curves for these effects were plotted. From these curves the concentration, which produced mortality to $50 \%$ of the embryos (lethal concentration 50 , $\mathrm{LC}_{50}$ ), and the concentration at which $50 \%$ of the embryos presented at least one dysmorphogenic feature (effective concentration 50 for dysmorphogenesis, $\mathrm{EC}_{50}$ ), were calculated.

\subsection{Pre-Exposure of the Embryos to Modulators of Antioxidant Status + Exposure to OS Inducers}

To elucidate the OS role in the developmental effects produced by OS inducers, another assay was performed by modulating the ZF embryos' OS responses through pre-exposure to the MTC of compounds which can affect OS conditions, and the posterior exposure to the working concentrations of OS inducers. NAC and L-NAME were used to potentiate antioxidant status, as NAC increases 
glutathione levels [30] and L-NAME inhibits nitric oxide production [31]. On the other hand, DEM and BSO were used to inhibit glutathione synthesis [32] by increasing the sensitivity of the embryos to OS.

At $2 \mathrm{hpf}$, embryos were pre-exposed to the MTC of modulators of antioxidant status for $24 \mathrm{~h}$, and then washed with $0.3 \times$ Danieau's buffer. At $26 \mathrm{hpf}$, embryos were exposed to OS inducers at the selected working concentrations. Lethality and dysmorphogenesis were evaluated as previously described, and concentration-response curves were plotted. A comparison of the concentration-response curves of pre-exposure to modulators of antioxidant status + exposure to OS inducers with concentration-response curves of OS inducers exposure was performed.

\subsection{Pre-Exposure of the Embryos to Antioxidant Compounds + Exposure to OS Inducer}

To detect the protective effects of chemicals against oxidant induced developmental toxicity in ZF embryos, different compounds with well determined antioxidant activity were assayed.

A pre-exposure to the MTC of vitamin (vit.) E, lipoic acid and quercetin was performed from 2 to $26 \mathrm{hpf}$, followed by a washing step with $0.3 \times$ Danieau's solution and the exposure to the working concentrations of the selected OS inducer for $24 \mathrm{~h}$. Evaluation of the embryos was performed as described before, and concentration-response curves were graphically represented. A comparison between the concentration-response curves of pre-exposure to antioxidants + exposure to the selected OS inducer with the concentration-response curve of the exposure to the selected OS inducer was performed.

\subsection{Data Evaluation}

Comparison of categorical variables was performed with the Fisher's exact test. Concentrationresponse curves for lethality and dysmorphogenesis were fitted to all the data using the Hill model in GraphPad Prism 6 software and compared with the extra sum-of-squares F test, which compares the parameters fit to datasets (GraphPad Software, La Jolla, CA, USA). Confidence intervals were set at 95\% and a probability of $p<0.05$ was considered as statistically significant.

\section{Results}

\subsection{Characterization of the Effects of Oxidative Stress Related Compounds in Zebrafish Embryos}

The results of the characterization of the lethal and dysmorphogenic effects produced by ZF embryos exposure to OS inducers, modulators and antioxidants are shown in Table 1. 
Table 1. Characterization of lethality and dysmorphogenesis in zebrafish embryos, produced by oxidative stress-related compounds.

\begin{tabular}{|c|c|c|c|c|c|}
\hline Compounds & $\begin{array}{c}\text { Range of } \\
\text { Concentrations }\end{array}$ & MTC & $\mathrm{LC}_{50}$ & $\mathrm{EC}_{50}$ & $\begin{array}{l}\text { Exposure } \\
\text { Window }\end{array}$ \\
\hline \multicolumn{6}{|c|}{ OS Inducers } \\
\hline $\begin{array}{l}\text { Tert-butyl hydroperoxide } \\
\text { (tBOOH) }\end{array}$ & $1-4 \mathrm{mM}$ & n.d. ${ }^{a}$ & $2.4 \mathrm{mM}$ & $1.6 \mathrm{mM}$ & $26-50 \mathrm{hpf}$ \\
\hline Tetrachlorohydroquinone (TCHQ) & 2.5-20 $\mu \mathrm{M}$ & n.d. ${ }^{a}$ & $16.0 \mu \mathrm{M}$ & $3.9 \mu \mathrm{M}$ & 26-50 hpf \\
\hline Lipopolysaccharides from & & & & & \\
\hline $\begin{array}{l}\text { Escherichia coli 0111:B4 } \\
\text { (LPS) }\end{array}$ & $5-60 \mu \mathrm{g} / \mathrm{mL}$ & $25 \mu \mathrm{g} / \mathrm{mL}$ & $50.1 \mu \mathrm{g} / \mathrm{mL}$ & $35.9 \mu \mathrm{g} / \mathrm{mL}$ & $26-50 \mathrm{hpf}$ \\
\hline \multicolumn{6}{|c|}{ Modulators of Antioxidant Status } \\
\hline $\begin{array}{l}\text { N-acetyl-L-cysteine } \\
\text { (NAC) }\end{array}$ & $50-2500 \mu \mathrm{M}$ & $250 \mu \mathrm{M}$ & $1874 \mu \mathrm{M}$ & $920.6 \mu \mathrm{M}$ & $2-26 \mathrm{hpf}$ \\
\hline $\begin{array}{c}\text { Diethyl maleate } \\
\text { (DEM) }\end{array}$ & $0.1-100 \mu \mathrm{M}$ & $0.5 \mu \mathrm{M}$ & n.d. ${ }^{\mathrm{b}}$ & $1.5 \mu \mathrm{M}$ & $2-26 \mathrm{hpf}$ \\
\hline $\begin{array}{c}N_{\omega} \text {-nitro L-arginine methyl ester } \\
\text { hydrochloride } \\
\text { (L-NAME) }\end{array}$ & $0.1-100 \mu \mathrm{M}$ & $5 \mu \mathrm{M}$ & n.d. ${ }^{\mathrm{c}}$ & $44.36 \mu \mathrm{M}$ & $2-26 \mathrm{hpf}$ \\
\hline $\begin{array}{l}\text { DL-buthionine sulfoximine } \\
\text { (BSO) }\end{array}$ & $1-5000 \mu \mathrm{M}$ & $50 \mu \mathrm{M}$ & n.d. ${ }^{c}$ & $2722 \mu \mathrm{M}$ & $2-26 \mathrm{hpf}$ \\
\hline \multicolumn{6}{|c|}{ Antioxidants } \\
\hline Vit. E & $1-1000 \mu \mathrm{M}$ & $100 \mu \mathrm{M}$ & n.d. ${ }^{\mathrm{d}}$ & n.d. ${ }^{\mathrm{d}}$ & $2-26 \mathrm{hpf}$ \\
\hline Lipoic acid & $0.1-1000 \mu \mathrm{M}$ & $5 \mu \mathrm{M}$ & $116.4 \mu \mathrm{M}$ & n.d. ${ }^{\mathrm{c}}$ & $2-26 \mathrm{hpf}$ \\
\hline Quercetin & $0.1-30 \mu \mathrm{M}^{\mathrm{e}}$ & $20 \mu \mathrm{M}$ & n.d. ${ }^{\mathrm{d}}$ & n.d. ${ }^{\mathrm{d}}$ & $2-26 \mathrm{hpf}$ \\
\hline
\end{tabular}

Range of tested concentrations, maximum tolerable concentration (MTC), lethal concentration 50 ( $\mathrm{LC}_{50}$ ), effective concentration 50 for dysmorphogenesis $\left(\mathrm{EC}_{50}\right)$ and exposure window for each of the studied compounds. n.d.: data were not determined. ${ }^{a}$ : MTC was not determined because the compound produced lethal or dysmorphogenic effects at all the studied concentrations. ${ }^{\mathrm{b}}: \mathrm{LC}_{50}$ was not calculated because no lethal effects were observed until the highest concentration, where lethality was of $100 \%$. ${ }^{c}$ : $\mathrm{LC}_{50}$ or $\mathrm{EC}_{50}$ was not calculated because no significant effects in the mortality of the embryos were observed. ${ }^{\mathrm{d}}: \mathrm{LC}_{50}$ and $\mathrm{EC}_{50}$ were not calculated because the compounds did not produce lethal or dysmorphogenic effects at any of the tested concentrations. ${ }^{\text {e: }}$ Quercetin solution precipitated from $30 \mu \mathrm{M}$. It was not possible to evaluate the effects at higher concentrations.

OS inducers produced developmental effects in zebrafish embryos (lethality and dysmorphogenic effects), which were concentration-dependent. Modulators of antioxidant status and antioxidants did not produce lethality at the studied concentrations, and the dysmorphogenic effects observed in the embryos exposed to the tested compounds were mainly developmental delay, cardiac oedema, and brain necrosis, which were not specific alterations. The only compound-specific effect was observed in TCHQ exposure, which produced an effect in the pigmentation of the embryos.

\subsection{Pre-Exposure to Modulators of Antioxidant Status + Exposure to OS Inducers}

We attempted to modulate the embryotoxic and lethal effects produced by OS inducers in zebrafish embryos by pre-exposing them to a set of known modulators of antioxidant status in zebrafish (Table 2), in order to evaluate if the effects produced by OS inducers were caused by an OS mechanism. 
Table 2. Lethality and dysmorphogenesis effective concentration values in zebrafish embryos on the modulation of developmental effects produced by OS inducers.

\begin{tabular}{|c|c|c|c|}
\hline Modulator of Antioxidant Status & OS Inducer & $\begin{array}{c}\mathrm{LC}_{50} \\
(95 \% \mathrm{CI})\end{array}$ & $\begin{array}{c}E_{50} \\
(95 \% \mathrm{CI})\end{array}$ \\
\hline None $^{1}$ & \multirow{5}{*}{$\begin{array}{c}\text { Tert-butyl hydroperoxide } \\
\text { (tBOOH) }\end{array}$} & $\begin{array}{c}2.38 \mathrm{mM} \\
(2.28-2.48)\end{array}$ & $\begin{array}{c}1.64 \mathrm{mM} \\
(1.44-1.87)\end{array}$ \\
\hline $\mathrm{N}$-acetyl-L-cysteine (NAC) & & n.d. & $\begin{array}{l}2.28 \mathrm{mM}^{* *} \\
(2.11-2.46)\end{array}$ \\
\hline $\begin{array}{c}N_{\omega} \text {-nitro L-arginine methyl ester } \\
\text { hydrochloride } \\
\text { (L-NAME) }\end{array}$ & & n.d. & $\begin{array}{l}3.17 \mathrm{mM}^{* * *} \\
(2.85-3.52)\end{array}$ \\
\hline $\begin{array}{l}\text { Diethyl maleate } \\
\text { (DEM) }\end{array}$ & & $\begin{array}{l}2.06 \mathrm{mM}^{*} \\
(1.78-2.38)\end{array}$ & $\begin{array}{l}1.17 \mathrm{mM}^{* *} \\
(1.07-1.29)\end{array}$ \\
\hline $\begin{array}{l}\text { DL-buthionine sulfoximine } \\
\text { (BSO) }\end{array}$ & & $\begin{array}{l}1.95 \mathrm{mM}^{* * *} \\
(1.85-2.05)\end{array}$ & $\begin{array}{l}1.20 \mathrm{mM}^{*} \\
(1.07-1.33)\end{array}$ \\
\hline None & \multirow{5}{*}{$\begin{array}{c}\text { Tetrachlorohydroquinone } \\
\text { (TCHQ) }\end{array}$} & $\begin{array}{c}15.2 \mu \mathrm{M} \\
(13.8-16.7)\end{array}$ & $\begin{array}{c}8.84 \mu \mathrm{M} \\
(7.15-10.9)\end{array}$ \\
\hline NAC & & $\begin{array}{c}19.6 \mu \mathrm{M}^{*} \\
(16.6-23.3)\end{array}$ & $\begin{array}{l}15.5 \mu \mathrm{M}^{* * *} \\
(14.8-16.3)\end{array}$ \\
\hline L-NAME & & $\begin{array}{c}19.0 \mu \mathrm{M}^{*} \\
(17.3-20.9)\end{array}$ & $\begin{array}{l}17.1 \mu \mathrm{M}^{* * *} \\
(16.9-17.3)\end{array}$ \\
\hline DEM & & $\begin{array}{l}9.78 \mu \mathrm{M}^{* *} \\
(7.31-13.1)\end{array}$ & $\begin{array}{c}4.79 \mu \mathrm{M}^{*} \\
(3.88-5.91)\end{array}$ \\
\hline BSO & & $\begin{array}{l}6.89 \mu \mathrm{M}^{* * *} \\
(6.13-7.75)\end{array}$ & $\begin{array}{l}4.17 \mu \mathrm{M}^{* *} \\
(3.62-4.81)\end{array}$ \\
\hline None $^{1}$ & \multirow{5}{*}{$\begin{array}{c}\text { Lipopolysaccharides } \\
\text { from Escherichia coli } \\
\text { 0111:B4 } \\
\text { (LPS) }\end{array}$} & $\begin{array}{l}50.1 \mu \mathrm{g} / \mathrm{mL} \\
(48.6-51.8)\end{array}$ & $\begin{array}{l}36.0 \mu \mathrm{g} / \mathrm{mL} \\
(28.4-45.6) \\
\end{array}$ \\
\hline NAC & & $\begin{array}{c}51.6 \mu \mathrm{g} / \mathrm{mL}^{*} \\
(48.8-54.5)\end{array}$ & $\begin{array}{c}39.6 \mu \mathrm{g} / \mathrm{mL} \\
(35.0-44.8)\end{array}$ \\
\hline L-NAME & & $\begin{array}{c}53.4 \mu \mathrm{g} / \mathrm{mL} \text { * } \\
(51.9-55.0)\end{array}$ & $\begin{array}{l}51.3 \mu \mathrm{g} / \mathrm{mL}^{* *} \\
(49.6-53.0)\end{array}$ \\
\hline DEM & & $\begin{array}{l}42.1 \mu \mathrm{g} / \mathrm{mL}^{* * *} \\
(37.9-46.8)\end{array}$ & $\begin{array}{l}31.1 \mu \mathrm{g} / \mathrm{mL} \\
(26.3-36.6)\end{array}$ \\
\hline $\mathrm{BSO}$ & & $\begin{array}{c}45.2 \mu \mathrm{g} / \mathrm{mL}^{* *} \\
(43.2-47.4)\end{array}$ & $\begin{array}{l}36.2 \mu \mathrm{g} / \mathrm{mL} \\
(29.4-44.5)\end{array}$ \\
\hline
\end{tabular}

Lethal concentration $50\left(\mathrm{LC}_{50}\right)$, effective concentration 50 for dysmorphogenesis $\left(\mathrm{EC}_{50}\right)$ and $95 \%$ confidence interval. Statistically significant differences with respect to the group, which was not exposed to any modulator: *: $p<0.05$; ${ }^{* *}: p<0.01$; ${ }^{* * *}: p<0.001$; n.d.: no lethality was observed; ${ }^{1} \mathrm{~A}$ unique $\mathrm{tBOOH}$ and LPS concentration-response curve was generated with the dissolution of the compounds in Danieau's buffer without DMSO and compared to all the concentration-response curves of the groups pre-exposed to chemicals (initially dissolved or not in DMSO) due to the lack of effect of DMSO in the embryonic development of ZF.

In embryos which were exposed to $\mathrm{tBOOH}$, a pre-exposure to NAC and L-NAME significantly drifted the $\mathrm{tBOOH}$ concentration-response curves to higher concentrations (Figure 1), the fact that, at the NAC and L-NAME pre-exposure group, no significant effects in mortality of the embryos were observed being of special importance. On the contrary, when ZF embryos where pre-exposed to DEM and BSO, a significant shift in the concentration-response curves to lower concentrations of $\mathrm{BOOH}$ was observed (Figure 1). As described before, the $\mathrm{tBOOH}$ concentration-response curve was generated after a pre-incubation of the embryos for $24 \mathrm{~h}$ in $0.3 \times$ Danieau's buffer without DMSO, due to the lack of effects of DMSO in ZF development. 


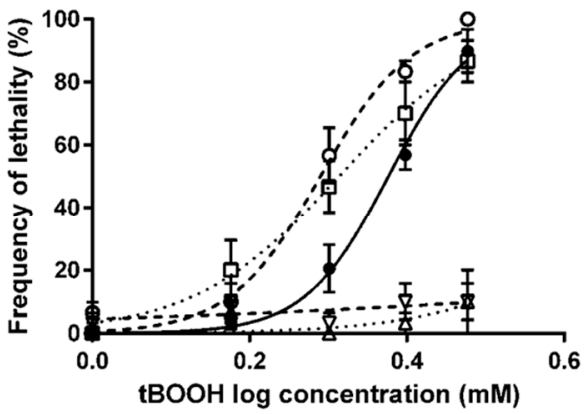

$\mathrm{tBOOH} \cdot \Delta \cdot \mathrm{NAC} 250 \mu \mathrm{M}+\mathrm{tBOOH} \quad \bullet \cdot \mathrm{DEM} 0.5 \mu \mathrm{M}+\mathrm{tBOOH}$

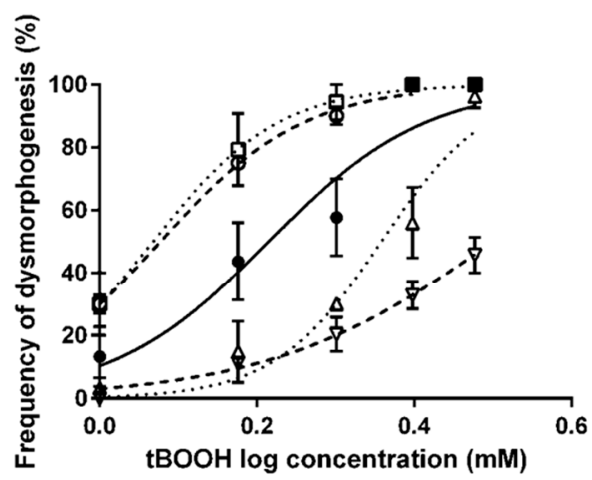

$-\nabla \cdot$ L-NAME $5 \mu \mathrm{M}+\mathrm{tBOOH}-\Theta \cdot \mathrm{BSO} 50 \mu \mathrm{M}+\mathrm{tBOOH}$

Figure 1. Concetration-response curves for lethality and dysmorphogenesis of tert-butyl hydroperoxide $(\mathrm{tBOOH})$ alone or in combination with modulators of antioxidant status.

The modulation of antioxidant status in embryos exposed to TCHQ presented similar results to $\mathrm{tBOOH}$. When ZF embryos were pre-exposed to NAC and L-NAME, the concentration-response curves for lethality and dysmorphogenesis were significantly shifted to higher concentrations of TCHQ (Figure 2). On the other hand, assays conducted with pre-exposure to DEM and BSO produced a statistically significant drift in the concentration-effect curves for lethality and dysmorphogenesis to lower concentrations of TCHQ (Figure 2).

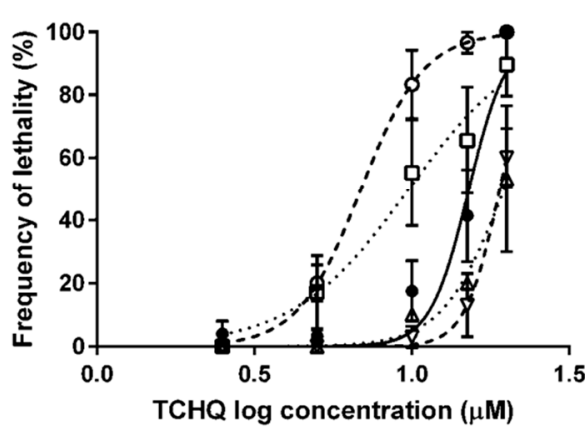

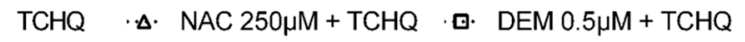

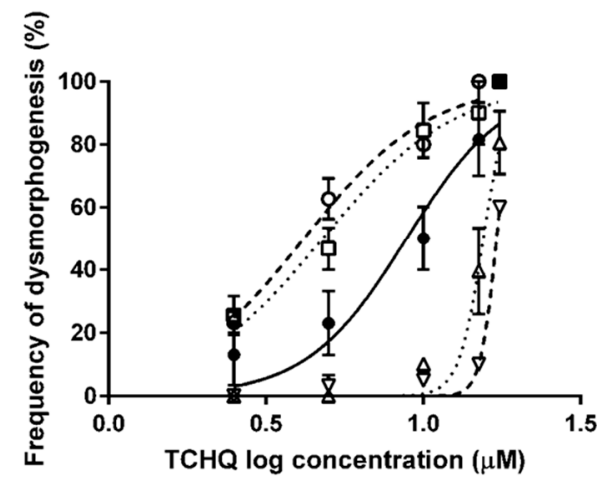

$-\nabla \cdot$ L-NAME $5 \mu \mathrm{M}+\mathrm{TCHQ} \quad-\Theta \cdot \mathrm{BSO} 50 \mu \mathrm{M}+\mathrm{TCHQ}$

Figure 2. Concentration-response curves for lethality and dysmorphogenesis of tetrachlorohydroquinone (TCHQ) alone or in combination with modulators of antioxidant status.

Pre-exposure of ZF embryos to NAC, DEM, L-NAME, and BSO followed by LPS exposure at the selected working concentrations shifted the lethality concentration-effect curves significantly. In the analysis of dysmorphogenic effects in ZF embryos, no significant effects were observed in embryos pre-exposed to NAC, DEM, and BSO, and subsequently exposed to LPS. Only a significant reduction in dysmorphogenic effects was observed in L-NAME pre-exposed embryos (Figure 3). As described in the previous section, embryos were pre-incubated with $0.3 \times$ Danieau's buffer without DMSO, followed by LPS exposure and calculation of the concentration-response curve, due to the lack of effects of DMSO in ZF development. 


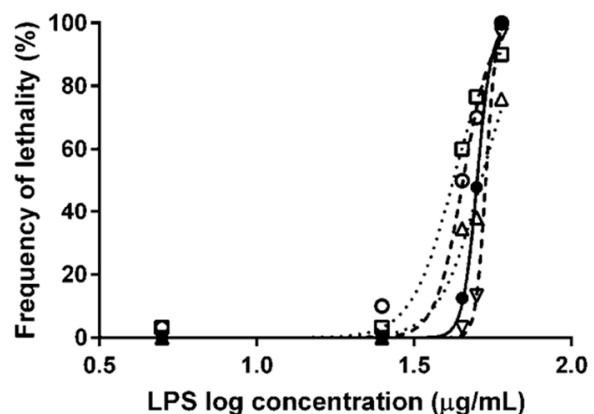

$\rightarrow$ LPS $\cdot \Delta \cdot$ NAC $250 \mu \mathrm{M}+$ LPS $\cdot \square \cdot$ DEM $0.5 \mu \mathrm{M}+$ LPS

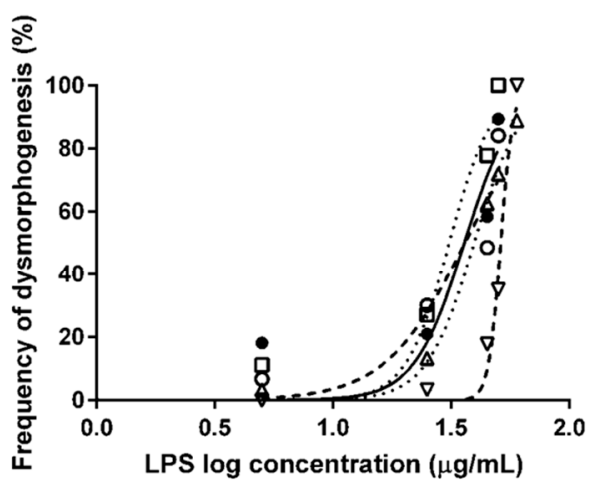

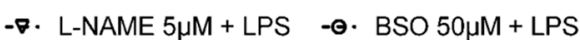

Figure 3. Concentration-response curves for lethality and dysmorphogenesis of lipopolysaccharides of Escherichia coli 0111:B4 (LPS) alone or in combination with modulators of antioxidant status.

The modulation of antioxidant status in embryos exposed to $\mathrm{tBOOH}$ produced more consistent results than other OS inducers. The observed effects in the embryonic development were general alterations not compound-specific. $\mathrm{tBOOH}$ was selected as the general OS inducer for the study of protective effects of antioxidant compounds.

\subsection{Detection of Protective Effects of Antioxidant Compounds in Zebrafish Embryos}

The second part of the study consisted in the use of $\mathrm{tBOOH}$ as a general OS inducer for the detection of compounds with very well-known antioxidant capacity. ZF embryos were exposed from 2 to $26 \mathrm{hpf}$ to antioxidant compounds (vit. E, lipoic acid, and quercetin), before exposing them to $\mathrm{BOOH}$ from 26 to $50 \mathrm{hpf}$.

In all cases, pre-exposure to the studied compounds produced a significant drift in the concentration-response curves of lethality and dysmorphogenesis to higher concentrations of $\mathrm{BOOH}$ (Figure 4), which may indicate an antioxidant effect.
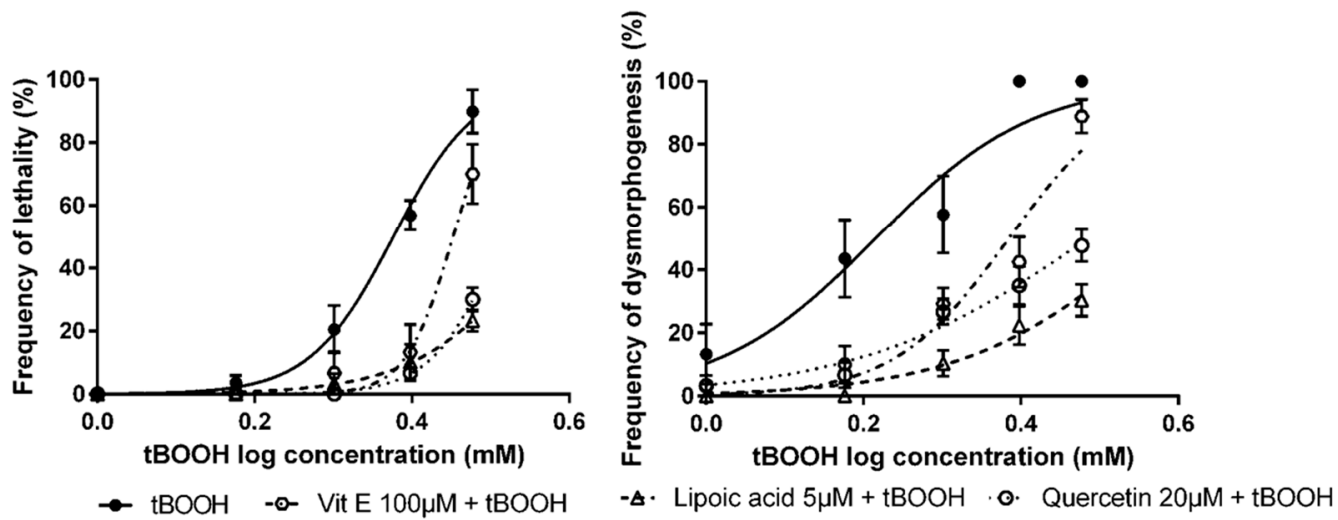

Figure 4. Concentration-response curves for lethality and dysmorphogenesis of $\mathrm{tBOOH}$ alone or in combination with different antioxidant compounds.

The $\mathrm{LC}_{50}$, after $\mathrm{tBOOH}$ exposure, was $2.38 \mathrm{mM}$, and values obtained after vit. E, lipoic acid, and quercetin exposure were $2.83 \mathrm{mM}, 3.72 \mathrm{mM}$, and $3.26 \mathrm{mM}$, respectively. For the $\mathrm{EC}_{50}$ values, the situation was similar, from $\mathrm{tBOOH}$ exposure, the $\mathrm{EC}_{50}$ was $1.64 \mathrm{mM}$, while pre-exposure to the studied compounds returned an $\mathrm{EC}_{50}$ of $2.42 \mathrm{mM}$ for vit. E, $3.70 \mathrm{mM}$ for lipoic acid and $3.05 \mathrm{mM}$ for quercetin (Table 3). 
Table 3. Effects of antioxidant compounds in lethality and dysmorphogenesis of zebrafish embryos exposed to $\mathrm{tBOOH}$.

\begin{tabular}{|c|c|c|c|}
\hline $\begin{array}{l}\text { Antioxidant } \\
\text { Compounds }\end{array}$ & OS Inducer & $\mathrm{LC}_{50}(95 \% \mathrm{CI})$ & $\mathrm{EC}_{50}(95 \% \mathrm{CI})$ \\
\hline None $^{1}$ & \multirow{4}{*}{$\begin{array}{l}\text { Tert-butyl hydroperoxide } \\
\text { (tBOOH) }\end{array}$} & $\begin{array}{c}2.38 \mathrm{mM} \\
(2.28-2.48)\end{array}$ & $\begin{array}{c}1.64 \mathrm{mM} \\
(1.44-1.87)\end{array}$ \\
\hline Vitamin E & & $\begin{array}{l}2.83 \mathrm{mM}^{* * *} \\
(2.70-2.69)\end{array}$ & $\begin{array}{c}2.42 \mathrm{mM}^{* * *} \\
(2.17-2.70)\end{array}$ \\
\hline Lipoic acid & & $\begin{array}{l}3.72 \mathrm{mM}^{* * *} \\
(3.14-4.40)\end{array}$ & $\begin{array}{l}3.70 \mathrm{mM}^{* * *} \\
(3.03-4.51)\end{array}$ \\
\hline Quercetin & & $\begin{array}{c}3.26 \mathrm{mM}^{* * *} \\
(2.83-3.76)\end{array}$ & $\begin{array}{c}3.05 \mathrm{mM}^{* * * *} \\
(2.64-3.54)\end{array}$ \\
\hline
\end{tabular}

Lethal concentration $50\left(\mathrm{LC}_{50}\right)$, effective concentration 50 for dysmorphogenesis $\left(\mathrm{EC}_{50}\right)$ and $95 \%$ confidence interval. Statistically significant differences with respect to the group which was not exposed to any antioxidant compound: ${ }^{* *}: p<0.001 ;{ }^{1} \mathrm{~A}$ unique $\mathrm{tBOOH}$ concentration-response curve was generated and compared to all the concentration-response curves of the antioxidants pre-exposure groups (initially dissolved or not in DMSO) due to the lack of effect of DMSO in the embryonic development of ZF.

\section{Discussion}

Oxygen is an essential element for cell life and, from its metabolism, some toxic derivatives are produced, such as ROS, which are highly reactive to biological molecules and can produce OS [33]. An important factor that could prevent OS effects is the alimentary antioxidants intake. For this reason, the study of antioxidant capacity of compounds has been gaining interest in the past few years. It has been postulated that, in order to evaluate the antioxidant potential, a method which includes in vivo techniques would have more impact on the results because OS implies mechanisms which depend on many system conditions, especially the kinetic part of the reactions [34]. We have proposed the ZF embryo test, which could be a valuable in vivo method to test the antioxidant capacity of compounds, with the main advantages of an in vitro technique.

In the first part of this study, we characterized the embryotoxic and dysmorphogenic effects of several compounds, which have an OS-related mechanism of action on the ZF embryos: $\mathrm{tBOOH}$, $\mathrm{TCHQ}$, and LPS. The induction of OS by $\mathrm{tBOOH}$ is due to its capacity to generate butoxyl radicals which deplete antioxidant systems and lead to cell death [35], and it has been previously used in ZF embryos to induce OS [36]. TCHQ can induce OS by producing superoxide radicals, favoring the depletion of the reduced glutathione concentrations [37], and it has also been observed that TCHQ can produce DNA strand breakage in cells [38]. LPS is a microbial product of bacteria and its contribution to ROS production has been studied as a secondary effect to inflammation [39]. It has been used as an OS inducer in different in vitro and in vivo models [40]. All the studied OS inducers produced a significant increase in lethality and in the production of dysmorphogenesis in the exposed ZF embryos.

In order to check if the observed effects in ZF embryos could be produced by an OS mechanism, we performed assays of modulation of the embryos' antioxidants statuses with compounds related to OS. The modulation was carried out through raising or decreasing the antioxidant defenses of the embryos with NAC and L-NAME, and DEM and BSO, respectively. NAC is an antioxidant compound, which is a rate-limiting substrate in glutathione synthesis, and it can also act as a scavenger of free radicals [41]. L-NAME is an inhibitor of nitric oxide synthase, the enzyme responsible for nitric oxide synthesis. As a result of this inhibition, it reduces the production of endogenous nitric oxide, which is a compound that can produce reactive nitrogen species and consequently, OS [30]. DEM is an alkylating agent that can produce a conjugation and depletion of glutathione [42], and it can also activate the nuclear factor (erythroid-derived 2)-like 2 (Nrf2) pathway [22], and BSO is an antioxidant molecule suppressor, which specifically inhibits $\gamma$-glutamyl cysteine synthetase, the enzyme for glutathione biosynthesis, and causes the depletion of glutathione levels [43]. 
In general terms, we have demonstrated that the lethal and dysmorphogenic effects of $\mathrm{tBOOH}$ and TCHQ were significantly reduced when the embryos were pre-treated with antioxidant compounds (NAC and L-NAME). From the opposite position, the observed effects in mortality and in dysmorphogenesis were significantly increased when ZF embryos were pre-exposed to compounds which decrease the antioxidant status (DEM and BSO). We could conclude that $\mathrm{tBOOH}$ and TCHQ produced their embryolethal and dysmorphogenic effects in ZF embryos by an OS mechanism of action. No significant effects in dysmorphogenesis related to OS were observed in the LPS treatment group. The observed effects in the lethality of ZF embryos exposed to LPS could be more related to its mechanism as an inflammation inducer [44] than as an OS mechanism. Nevertheless, the effects of these compounds, associated with an OS mechanism, should be verified by analyzing parameters directly related to OS, like evaluation of the expression of OS-related genes in the exposed ZF embryos.

Because of its consistent results, $\mathrm{tBOOH}$ was selected as the OS inducer to be used to evaluate the antioxidant potential of compounds. To validate the use of $\mathrm{tBOOH}$ to detect the protective effects of antioxidant compounds, ZF embryos were pre-exposed to diverse compounds with a well-established antioxidant capacity (vit. E, lipoic acid, and quercetin) and posteriorly exposed to $\mathrm{tBOOH}$. In addition, a statistical analysis was performed by comparing the concentration-effect curves for lethality and for dysmorphogenesis obtained in both experiments: $\mathrm{tBOOH}$ alone and antioxidants $+\mathrm{tBOOH}$.

Vit. E is a compound with free-radical scavenging activity, which leads to an antioxidant action that has been demonstrated in vitro [45]. Lipoic acid is a thiol regenerating compound, which increases the level of glutathione. It inhibits the formation of hydroxyl radicals, and it also scavenges ROS [46]. Quercetin is a flavonol found in apples, tea, and onions, and exerts its antioxidant effect through different bioactive effects. Its main antioxidant mechanism of action is through quenching different radicals, such as hydroxyl, peroxyl, and superoxide, as well as nitric oxide and lipid oxidation [5]. Quercetin can induce antioxidant gene expression through the activation of Nrf2 [47]. Among these, quercetin can also modulate mitochondrial biogenesis by reducing ROS production in various cell types [48]. The pre-exposure of the embryos to vit. E, quercetin, and lipoic acid, followed by the exposure to the OS inducer, has confirmed the protective effects of well-known antioxidant compounds against oxidant-induced developmental toxicity in ZF. In all the cases, the pre-exposure of ZF embryos to the compounds followed by the exposure to the selected concentrations of $\mathrm{tBOOH}$ produced a significant shift of the concentration-effect curves of lethality and dysmorphogenesis. These results indicated the preventive effect of vit. E, lipoic acid, and quercetin against the toxic effects of $\mathrm{tBOOH}$, which were related to an OS mechanism of action. The antioxidant effect of these compounds versus oxidant effects produced by the OS inducer should be confirmed by the application of antioxidant capacity evaluation methods.

The ZF embryo test has been widely used to study different types of compounds, including OS-related chemicals. Recently, a new stable transgenic line has been developed for the rapid detection of oxidative stress, although it has not been systematically tested to evaluate the antioxidant capacity of chemicals [49]. The results of our study are similar to those observed by the authors in [25], in which they observed the protective effect of vit. E in ZF embryos exposed to PCB126, which causes OS. There are other studies in which they evaluated the effects of compounds, which may have part of its mechanism of action related to oxidative injury, such as ethanol, in ZF embryos [19]. In this case, they analyzed and confirmed the partial prevention of ethanol-induced cardiovascular disfunction by lipoic acid in ZF embryos. Natural antioxidant compounds, such as quercetin, have demonstrated their antioxidant capacity and their protective activity against different diseases using the ZF embryo test [12], reinforcing the results obtained in our study.

\section{Conclusions}

The ZF embryo has been established as the basis for the study of the modulative and protective effects of antioxidant compounds in oxidant induced developmental toxicity in ZF. An experimental design using $\mathrm{tBOOH}$ as an $\mathrm{OS}$ inducer has been developed in the present study. The evaluation of the 
OS-related effects produced by $\mathrm{tBOOH}$ was estimated by a modulation of the antioxidant status assay with NAC, L-NAME, DEM, and BSO. The study of the protective effects of antioxidant compounds was performed with pre-exposure of ZF embryos to vit. E, lipoic acid, and quercetin, which are compounds with a well-established antioxidant capacity, and the protective effect of these compounds on developmental effects in the embryos was confirmed.

Our experimental system could be used as a valuable in vivo tool for testing compounds with presumable antioxidant activity, with advantages in respect to other techniques used in the evaluation of the antioxidant capacity (analytical or cell-based assays).

Further studies should be done to extensively characterize the effects of $\mathrm{tBOOH}$ as an OS inducer, as well as to evaluate the antioxidant capacity of compounds, in order to establish an OS model based on ZF embryos to study new antioxidant compounds and the mechanism of action by which they exert their antioxidant activity.

Author Contributions: Conceptualization, N.B., E.T., E.P., J.M.L., and J.G.-C.; Formal analysis, N.B., E.T., E.P., and J.G.-C.; Funding acquisition, J.M.L.; Investigation, N.B. and J.G.-C.; Methodology, N.B., E.T., and E.P.; Project administration, J.M.L. and J.G.-C.; Resources, J.M.L. and J.G.-C.; Supervision, E.P., J.M.L., and J.G.-C.; Validation, N.B., E.T., E.P., J.M.L., and J.G.-C.; Visualization, N.B., E.T., E.P., J.M.L., and J.G.-C.; Writing-original draft, N.B.; Writing-review and editing, N.B., E.T., E.P., J.M.L., and J.G.-C. All authors have read and agreed to the published version of the manuscript.

Funding: This research received no external funding.

Conflicts of Interest: The authors declare no conflict of interest.

\section{References}

1. Valko, M.; Rhodes, C.J.; Moncol, J.; Izakovic, M.; Mazur, M. Free radicals, metals and antioxidants in oxidative stress-induced cancer. Chem. Biol. Interact. 2006, 160, 1-40. [CrossRef]

2. Gülçin, I. Antioxidant activity of food constituents: An overview. Arch. Toxicol. 2012, 86, 345-391. [CrossRef]

3. Dröge, W. Free radicals in the physiological control of cell function. Physiol. Rev. 2002, 82, 47-95. [CrossRef]

4. Valko, M.; Leibfritz, D.; Moncol, J.; Cronin, M.T.D.; Mazur, M.; Telser, J. Free radicals and antioxidants in normal physiological functions and human disease. Int. J. Biochem. Cell Biol. 2007, 39, 44-84. [CrossRef]

5. Albarracin, S.L.; Stab, B.; Casas, Z.; Sutachan, J.J.; Samudio, I.; Gonzalez, J.; Gonzalo, L.; Capani, F.; Morales, L.; Barreto, G.E. Effects of natural antioxidants in neurodegenerative disease. Nutr. Neurosci. 2012, 15, 1-9. [CrossRef]

6. Prior, R.L.; Wu, X.; Schaich, K. Standardized methods for the determination of antioxidant capacity and phenolics in foods and dietary supplements. J. Agric. Food Chem. 2005, 53, 4290-4302. [CrossRef]

7. Becker, K.; Schroecksnadel, S.; Gostner, J.; Zaknun, C.; Schennach, H.; Überall, F.; Fuchs, D. Comparison of in vitro tests for antioxidant and immunomodulatory capacities of compounds. Phytomedicine 2014, 21, 164-171. [CrossRef] [PubMed]

8. Frankel, E.N.; Finley, J.W. How to standardize the multiplicity of methods to evaluate natural antioxidants. J. Agric. Food Chem. 2008, 56, 4901-4908. [CrossRef] [PubMed]

9. Chagas, P.M.; Weber Fulco, B.D.C.; Pesarico, A.P.; Roehrs, J.A.; Wayne, N.C. Bis(phenylimidazolselenazolyl) diselenide as an antioxidant compound: An in vitro and in vivo study. Chem. Biol. Interact. 2015, 233, 14-24. [CrossRef] [PubMed]

10. Speroni, E.; Guerra, M.C.; Minghetti, A.; Crespi-Perellino, N.; Pasini, P.; Piazza, F.; Roda, A. Oleuropein evaluated in vitro and in vivo as an antioxidant. Phyther. Res. 1998, 12, 14-24. [CrossRef]

11. Phulara, S.C.; Shukla, V.; Tiwari, S.; Pandey, R. Bacopa monnieri promotes longevity in caenorhabditis elegans under stress conditions. Pharmacogn. Mag. 2015, 11, 410-416. [PubMed]

12. Zhang, Z.J.; Cheang, L.C.V.; Wang, M.W.; Lee, S.M.Y. Quercetin exerts a neuroprotective effect through inhibition of the iNOS/NO system and pro-inflammation gene expression in PC12 cells and in zebrafish. Int. J. Mol. Med. 2011, 27, 195-203. [PubMed]

13. Bugel, S.M.; Tanguay, R.L.; Planchart, A. Zebrafish: A marvel of high-throughput biology for 21st century. Toxicol. Curr. Environ. Heal. Rep. 2014, 1, 341-352. [CrossRef] 
14. De Esch, C.; Slieker, R.; Wolterbeek, A.; Woutersen, R.; de Groot, D. Zebrafish as potential model for developmental neurotoxicity testing. A mini review. Neurotoxicol. Teratol. 2012, 34, 545-553. [CrossRef] [PubMed]

15. Rubinstein, A.L. Zebrafish: From disease modeling to drug discovery. Curr. Opin. Drug Discov. Devel. 2003, 6, 218-223.

16. Scholz, S.; Fischer, S.; Gündel, U.; Küster, E.; Luckenbach, T.; Voelker, D. The zebrafish embryo model in environmental risk assessment-Applications beyond acute toxicity testing. Environ. Sci. Pollut. Res. 2008, 15, 394-404. [CrossRef]

17. Park, K.H.; Cho, K.H. A zebrafish model for the rapid evaluation of pro-oxidative and inflammatory death by lipopolysaccharide, oxidized low-density lipoproteins, and glycated high-density lipoproteins. Fish Shellfish Immunol. 2011, 31, 904-910. [CrossRef]

18. Kishi, S.; Bayliss, P.E.; Uchiyama, J.; Koshimizu, E.; Qi, J.; Nanjappa, P.; Imamura, S.; Islam, A.; Neuberg, D.; Amsterdam, A.; et al. The identification of zebrafish mutants showing alterations in senescence-associated biomarkers. PLoS Genet. 2008, 4, e1000152. [CrossRef]

19. Reimers, M.J.; La Du, J.K.; Periera, C.B.; Giovanini, J.; Tanguay, R.L. Ethanol-dependent toxicity in zebrafish is partially attenuated by antioxidants. Neurotoxicol. Teratol. 2006, 28, 497-508. [CrossRef]

20. Xi, Y.; Noble, S.; Ekker, M. Modeling neurodegeneration in zebrafish. Curr. Neurol. Neurosci. Rep. 2011, 11, 274-282. [CrossRef]

21. Bakkers, J. Zebrafish as a model to study cardiac development and human cardiac disease. Cardiovasc. Res. 2011, 91, 279-288. [CrossRef] [PubMed]

22. Nakajima, H.; Nakajima-Takagi, Y.; Tsujita, T.; Akiyama, S.I.; Wakasa, T.; Mukaigasa, K.; Kaneko, H.; Tamaru, Y.; Yamamoto, M.; Kobayashi, M. Tissue-restricted expression of Nrf2 and its target genes in zebrafish with gene-specific variations in the induction profiles. PLoS ONE 2011, 6, e26884. [CrossRef] [PubMed]

23. Timme-Laragy, A.R.; Karchner, S.I.; Franks, D.G.; Jenny, M.J.; Harbeitner, R.C.; Goldstone, J.V.; McArthur, A.G.; Hahn, M.E. Nrf2b, novel zebrafish paralog of oxidant-responsive transcription factor NF-E2-related factor 2 (NRF2). J. Biol. Chem. 2012, 287, 4609-4627. [CrossRef] [PubMed]

24. Cordero, M.D.; Moreno-Fernández, A.M.; Gomez-Skarmeta, J.L.; de Miguel, M.; Garrido-Maraver, J.; Oropesa-Ávila, M.; Rodríguez-Hernández, Á.; Navas, P.; Sánchez-Alcázar, J.A. Coenzyme Q10 and alpha-tocopherol protect against amitriptyline toxicity. Toxicol. Appl. Pharmacol. 2009, 235, 329-337. [CrossRef] [PubMed]

25. Na, Y.R.; Seok, S.H.; Baek, M.W.; Lee, H.Y.; Kim, D.J.; Park, S.H.; Lee, H.K.; Park, J.H. Protective effects of vitamin E against 3,3',4,4',5-pentachlorobiphenyl (PCB126) induced toxicity in zebrafish embryos. Ecotoxicol. Environ. Saf. 2009, 72, 714-719. [CrossRef] [PubMed]

26. Kais, B.; Schneider, K.E.; Keiter, S.; Henn, K.; Ackermann, C.; Braunbeck, T. DMSO modifies the permeability of the zebrafish (Danio rerio) chorion-Implications for the fish embryo test (FET). Aquat. Toxicol. 2013, 140-141, 229-238. [CrossRef]

27. Kimmel, C.B.; Ballard, W.W.; Kimmel, S.R.; Ullmann, B.; Schilling, T.F. Stages of embryonic development of the zebrafish. Dev. Dyn. 1995, 203, 253-310. [CrossRef]

28. Nagel, R. DarT: The embryo test with the Zebrafish Danio rerio-a general model in ecotoxicology and toxicology. ALTEX 2002, 19, 38-48.

29. Teixidó, E.; Piqué, E.; Gómez-Catalán, J.; Llobet, J.M. Assessment of developmental delay in the zebrafish embryo teratogenicity assay. Toxicol. Vitr. 2013, 27, 469-478. [CrossRef]

30. Chen, T.H.; Lin, C.Y.; Tseng, M.C. Behavioral effects of titanium dioxide nanoparticles on larval zebrafish (Danio rerio). Mar. Pollut. Bull. 2011, 63, 303-308. [CrossRef]

31. Holmberg, A.; Olsson, C.; Holmgren, S. The effects of endogenous and exogenous nitric oxide on gut motility in zebrafish Danio rerio embryos and larvae. J. Exp. Biol. 2006, 209, 2472-2479. [CrossRef] [PubMed]

32. Usenko, C.Y.; Harper, S.L.; Tanguay, R.L. Fullerene C60 exposure elicits an oxidative stress response in embryonic zebrafish. Toxicol. Appl. Pharmacol. 2008, 229, 44-55. [CrossRef] [PubMed]

33. Halliwell, B.; Gutteridge, J. Free radicals and antioxidant protection: Mechanisms and significance in toxicology and disease. Hum. Toxicol. 1988, 7, 7-13. [CrossRef] [PubMed]

34. Prieto, M.A.; Murado, M.A. A critical point: The problems associated with the variety of criteria to quantify the antioxidant capacity. J. Agric. Food Chem. 2014, 62, 5472-5484. [CrossRef] 
35. Kanupriya; Prasad, D.; Sai Ram, M.; Sawhney, R.C.; Ilavazhagan, G.; Banerjee, P.K. Mechanism of tert-butylhydroperoxide induced cytotoxicity in U-937 macrophages by alteration of mitochondrial function and generation of ROS. Toxicol. Vitr. 2007, 21, 846-854. [CrossRef]

36. Timme-Laragy, A.R.; Van Tiem, L.A.; Linney, E.A.; Di Giulio, R.T. Antioxidant responses and NRF2 in synergistic developmental toxicity of PAHs in zebrafish. Toxicol. Sci. 2009, 109, 217-227. [CrossRef]

37. Wang, Y.J.; Ho, Y.S.; Chu, S.W.; Lien, H.J.; Liu, T.H.; Lin, J.K. Induction of glutathione depletion, p53 protein accumulation and cellular transformation by tetrachlorohydroquinone, a toxic metabolite of pentachlorophenol. Chem. Biol. Interact. 1997, 105, 1-16. [CrossRef]

38. Wang, Y.J.; Lee, C.C.; Chang, W.C.; Liou, H.B.; Ho, Y.S. Oxidative stress and liver toxicity in rats and human hepatoma cell line induced by pentachlorophenol and its major metabolite tetrachlorohydroquinone. Toxicol. Lett. 2001, 122, 157-169. [CrossRef]

39. Zhao, L.; Chen, Y.H.; Wang, H.; Ji, Y.L.; Ning, H.; Wang, S.F.; Zhang, C.; Lu, J.W.; Duan, Z.H.; Xu, D.X. Reactive oxygen species contribute to lipopolysaccharide-induced teratogenesis in mice. Toxicol. Sci. 2008, 103, 149-157. [CrossRef]

40. Kim, Y.S.; Kim, E.K.; Jeon, N.J.; Ryu, B.I.; Hwang, J.W.; Choi, E.J.; Moon, S.H.; Jeon, B.T.; Park, P.J. Antioxidant effect of Taurine-Rich Paroctopus dofleini extracts through inhibiting ROS production against LPS-induced oxidative stress in vitro and in vivo model. Adv. Exp. Med. Biol. 2017, 975, 1165-1177.

41. Kerksick, C.; Willoughby, D. The antioxidant role of glutathione and N-acetyl-cysteine supplements and exercise-induced oxidative stress. J. Int. Soc. Sports Nutr. 2005, 2, 38-44. [CrossRef] [PubMed]

42. Priya, S.; Nigam, A.; Bajpai, P.; Kumar, S. Diethyl maleate inhibits MCA+TPA transformed cell growth via modulation of GSH, MAPK, and cancer pathways. Chem Biol Interact. 2014, 219, 37-47. [CrossRef] [PubMed]

43. Griffith, O.W. Mechanism of action, metabolism, and toxicity of buthionine sulfoximine and its higher homologs, potent inhibitors of glutathione synthesis. J. Biol. Chem. 1982, 257, 13704-13712. [PubMed]

44. Novoa, B.; Bowman, T.V.; Zon, L.; Figueras, A. LPS response and tolerance in the zebrafish (Danio rerio). Fish Shellfish Immunol. 2009, 26, 326-331. [CrossRef] [PubMed]

45. Davis, S.; Davis, B.M.; Richens, J.L.; Vere, K.A.; Petrov, P.G.; Winlove, C.P.; O'shea, P. $\alpha$-Tocopherols modify the membrane dipole potential leading to modulation of ligand binding by P-glycoprotein 4. J. Lipid. Res. 2015, 56, 1543-1550. [CrossRef] [PubMed]

46. Maczurek, A.; Hager, K.; Kenklies, M.; Sharman, M.; Martins, R.; Engel, J.; Carlson, D.A.; Münch, G. Lipoic acid as an anti-inflammatory and neuroprotective treatment for Alzheimer's disease. Adv. Drug Deliv. Rev. 2008, 60, 13-14. [CrossRef]

47. Miyamoto, N.; Izumi, H.; Miyamoto, R.; Kondo, H.; Tawara, A.; Sasaguri, Y.; Kohno, K. Quercetin induces the expression of peroxiredoxins 3 and 5 via the Nrf2/NRF1 transcription pathway. Invest. Ophthalmol Vis. Sci. 2011, 22, 1055-1063. [CrossRef]

48. Rayamajhi, N.; Kim, S.-K.; Go, H.; Joe, Y.; Callaway, Z.; Kang, J.-G.; Ryter, S.; Chung, H. Quercetin induces mitochondrial biogenesis through activation of HO-1 in HepG2 cells. Oxidative Med. Cell. Longev. 2013, 2013, 154279. [CrossRef]

49. Mourabit, S.; Fitzgerald, J.A.; Ellis, R.P.; Takesono, A.; Porteus, C.S.; Trznadel, M.; Metz, J.; Winter, M.J.; Kudoh, T.; Tyler, C.R. New insights into organ-specific oxidative stress mechanisms using a novel biosensor zebrafish. Environ. Int. 2019, 133, 105138. [CrossRef]

(C) 2020 by the authors. Licensee MDPI, Basel, Switzerland. This article is an open access article distributed under the terms and conditions of the Creative Commons Attribution (CC BY) license (http://creativecommons.org/licenses/by/4.0/). 